\title{
Humanismo en "La Casa de Asterión", de Jorge Luis Borges (Ruptura del código estético)
}

\author{
Wilbert Arguedas Pizarro*
}

\begin{abstract}
RESUMEN
Estar dentro o fuera del código social, pasar por el filtro de la soledad, constituirse en personaje en crisis permanente, son aspectos que se analizan en este artículo, y que permiten dar cuenta de la construcción de un mundo literario, en donde el lector es también parte importante como productor de sentido. A partir de un texto de Borges, y de la concepción filosófica de su hacer literario, "La casa de Asterión" plantea un juego de intrigas, en donde lo humano permea cada línea, en donde el deseo de eternidad es una búsqueda permanente.
\end{abstract}

Palabras clave: humanismo, estética, comunicación, lector, escritor.

\begin{abstract}
Humanism in "The Asterion's House", by: Jorge Luis Borges. (Esthetic code breach). Being inside or outside of the social code, going through the filter of solitude, becoming a character in a permanent crisis, are aspects that are analyzed in this chapter and that account for the construction of a literary world in which the lector also has an important part as the producer of meaning. From a Borges text and from the philosophical conception of his literary work, "The Asterion's House" brings up an intriguing game, in which the human permeates each line, in which the desire of eternity is a permanent search.
\end{abstract}

Key words: Humanism, esthetic, communication, lector, writer.

\section{I}

El lector de este texto, al finalizar su lectura, se habrá preguntado si es válido confrontar la literatura -para usar un antiguo concepto formalista: la literariedad o la inmanencia- y lo externo a ella para determinar la

\footnotetext{
* Licenciado en Literatura y Lenguaje. Profesor de español y literatura en secundaria. Tutor de la Universidad Estatal a Distancia.
} 
significación del texto mismo, o si lo importante es dejarse llevar por la ficcionalidad fantástica del texto de Borges. O, sin la contratapa del realismo, el cuento no tendría cómo sostener una referencialidad externa a ella en razón de sentir comodidad. De este último escaño puede el lector inferir o esclarecer que la propuesta inclusión-exclusión como una lectura posible es válida. Y más allá, es válido que un docente de la enseñanza del Español (investido de crítico literario) intervenga el texto literario como si este fuera una espuma a la que se puede extraer cualquier líquido vigoroso, es decir: proponer una instrumentalización de la literatura como si fuera una pedagogía progresista, de vanguardia o humanitaria, por decirlo de alguna forma. $\mathrm{Al}$ menos en Costa Rica esto no es nada de extrañar. Aquí es de viejo cuño saber que el docente de la materia de Español debe impartir lecciones de redacción, gramática, humanidad, literatura en sus diversas modalidades, comunicación y otras más, cuando en otros países hay un especialista para cada una de ellas. Ya sabemos que la especialización es un rasgo de la posmodernidad y eso lo explica todo frente a la totalidad o globalidad del currículo nacional que enseña de todo y nada, a la vez; es una especie de vieja Ilustración pedagógica venida de Francia en los albores de la época poscolonial, de donde viene, incluso, el término liceo.
¿Pero tiene sentido esta propuesta? ¿El metalenguaje de la crítica literaria permitiría esta mezcla? Por el contrario, ¿la pedagogía de la inclusión como metadiscurso por competencias permitirá también esta mixtura? ¿Ambos la rechazan? ¿Puede hablarse de eclecticismo como un escapismo o un asunto de acomodo? Como sea, sin demeritar a la pedagogía de la inclusión por sus valores de integración humana, política, cultural y social, y muchas más, cae bien ensayar una lectura como la que se ha hará de "La casa de Asterión". No, sin embargo, decir que esta propuesta es peligrosa para la crítica literaria canónica.

En todo caso, el discurso literario queda establecido como tal y el pedagógico también. Este ensayo no es un ejemplo de cruces desafiantes de cada uno sino integradores. Valga decir que la significación última la dará el lector desde el provecho que le quiera sacar, o ninguno, si es el caso.

Quede claro que esta no es una evasión clásica en el aspecto más subjetivo de todo ensayo. Tampoco es responder a una cosa con otra y luego quedarse con nada. Se insiste: lo que se desea construir es una articulación discursiva (doxa u opinión) más que teórica (episteme) en rigor o una doctrina. Se busca reflejar la correlación significativa entre un discurso estético y otro pedagógico para dar luz sobre un aspecto de la vida social y 
humana: la exclusión del otro diferente al yo y cómo ambos discursos intentan instaurar otro código ético y social: la armonía en la inclusión y la humanización del nosotros.

El método de abordaje quiere ser simple, quizás más descriptivo que meta-teórico. Más lleno de dudas y contradicciones que llano, lineal, objetivo. Sí es bueno ver en este método una línea de trabajo que intenta describir un ideario estético de Borges y el de la pedagogía de la inclusión. Es pues un método reiterativo porque ese es el que se usa en pedagogía clásica y es descriptivo de la significación ficcional porque es el más cómodo en la crítica literaria tradicional. Lo importante es que el lector no quede enredado en las brumas de un discurso obsesivo. Como todo, uno escribe para uno mismo, para entrever intuiciones; luego, el otro se suma y ve las suyas.

Por decirlo de otro modo, "son apuntes sobre...", sea un aspecto interno de lo literario (la ficcionalidad) y sobre una visión integradora de la sociedad en general, llámese como quiera: Derechos Humanos, Políticos, Sociales, Pedagógicos... que opera "con, a la par de y sobre" la ética y la ontología del escritor (y sobre el diario vivir de este) de cualquier forma, sea: estética, metafísica, psicológica, existencialista, racionalista, idealista, pedagógica, humanística... En una esfera englobante todo escritor tiene algo que decir de la pedagogía, no por nada se les llamó de forma dogmática y sacra maestro de la palabra. Pero también de la imaginación y la significación. Hay quien afirma que la palabra no literaria de un escritor poco dice sobre la significación de su propia obra debido al tamiz o al sesgo que pueda incluir. Pero es bien sabido que un escritor en sus conferencias, cartas, anécdotas, escritos críticos, pedagógicos, misceláneos, entre varios, remite a claves de actualidad sobre su propia obra $\mathrm{y}$, en última instancia, sobre la vida misma del ser humano que es el referente fundamental sobre el porqué se escribe y sostiene, asimismo, la existencia de la profesión literaria y el destino que le sobrevendrá al oficiante de escritor.

En un tema, la incomunicación es un factor de exclusión social en el relato de Borges. En otro, la exclusión es un tema de tratamiento pedagógico que se puede abordar desde el punto de vista de los valores transversales presentes en los programas nacionales de estudio. En tercera opción, la incomunicación y la exclusión social son aspectos que se entrelazan en este relato para dar una luz sobre la propuesta estética de "La casa de Asterión", de Jorge Luis Borges, y, cómo se puede releer este texto en los programas de estudio de cara a una nueva propuesta social y ética.

Vale decir que este trabajo no es exclusivamente un análisis literario 
en rigor tal como se puede entender por "análisis literario" y tampoco es una exégesis pedagógica. Sin embargo, ambas cosas, de manera aglutinadora, se remiten una a otra. Es una visión complementaria o ecléctica que navega por lo histórico, lo sociológico, lo anecdótico, entre otros discursos complementarios.

\section{II}

La exclusión es una discriminación, un rótulo y una etiqueta determinista centrada, entre otras cosas, en la apariencia física o en la impericia para comunicarse, lo cual se ve como un déficit. Tal es el caso del minotauro, visto como un monstruo y como un ser que no pudo aprender a leer. Nuestra sociedad de consumo ve la belleza física como un privilegio de inserción y quien no la posea es sujeto de destierro.

Ante lo anterior el mundo ve la discapacidad o la diversidad como una enfermedad y no como una condición. De tal manera el minotauro actúa en contra de esta hostilidad con la burla. De esta forma, la incapacidad del sistema social para dar apoyo e incluir al minotauro se traslada al individuo, victimándolo. La razón es diversa. Por ejemplo hay una desigualdad cultural entre el minotauro y el vulgo-plebeyo. Este es de origen real, lo que también indica desigualdad en función del origen socioeconómico.
Sin embargo, lo mejor es hablar de diferencias culturales o socioeconómicas como fuente de enriquecimiento y de desarrollo en el sentido de que de la diversidad se puede sacar algo positivo y no verla como un mal o como un sujeto de rechazo, tal como le acontece al minotauro y la histeria colectiva que se desata al salir por la tarde a dar una vuelta por la ciudad.

Es decir, que las diferencias o la diversidad dan valor a las identidades desde el punto de vista ideológico, ético y moral, como se verá más adelante en el cuento, oponiéndose a la discriminación que sufre el minotauro. O sea, que hay que reconocer, al menos, un valor al monstruo: su diversidad es la razón de su rechazo porque representa lo que el mundo no quiere ser, lo que odia ser. A manera de hipótesis se sugiere la idea de que en un mundo lleno de diferencias no existe la normalidad. De aquí hay un desplazamiento hacia la interpretación que se propone del relato de Borges como una ruptura del código tradicional del mito a la luz del problema de la exclusión y la inclusión como modelo selectivo.

Entonces otro origen de la discriminación es la hipocresía como es evidente en el castigo social de Pasifae y el Toro Blanco, cuyo hijo es el minotauro. Desde este punto de vista, se propone una inclusión como un movimiento de conciencia social. Para esto se necesita un 
marco pedagógico para preparar a la sociedad. Quizá sea una concepción de la educación como neosubversiva / neoalternativa.

Asterión era un rey y el minotauro es el hijo de una reina que lleva el nombre del rey sin ser su hijo legitimo. Lo curioso es ver a estos dos seres como uno solo, al hijo y al rey, por su nombre como un tributo. Interesa ubicarlo en el espacio físico y en su condición humanizada. Una axiología de Asterión por el camino de la razón ética y moral serviría para ser justo con él, opuesta a cualquier forma de discriminación en el ámbito social por razones personales, culturales o sociales; como tal reconoce la inclusión: como un derecho al que él debe tener acceso y todos deben aceptarlo, independientemente de su condición y a la diversidad como un valor a partir del cual se debe reconocer por eso, por diverso, no como una amenaza o problema social. Esta última visión tradicional de la diversidad es la que encarna Teseo al aniquilar al minotauro ${ }^{1}$.

Lo que no debe ser la exclusión social en la conformación de esta manera de mirar a Asterión, es la conducta de Ariadna y Teseo. Al no haber un compromiso social para asumir la incapacidad salvo eliminarlo. Tomando prestadas las palabras de Minor Calderón ${ }^{2}$, en el trasfondo es un cuento de problemática política; y yo le agrego: cultural, económica, social e ideológica.

Por consiguiente ese trasfondo da pie para proponer la visión inclusiva planteada como ruptura de prejuicios, que establece la organización de sistemas de apoyo y desarrollo de una sociedad inclusiva que señala la conformación de una sociedad con un nuevo modelo sociodemocrático.

En esta propuesta se instaura una voz narrativa (en apariencia) distanciada, oscilante, vacilante, objetiva quizá, entre ser parte de la inclusión o la exclusión. No es una

1. Con palabras del mismo Borges (1975), Teseo viene a ser una suerte de “espantoso y atroz redentor" para el monstruo Asterión. Más adelante agrega algo sobre Morell que sirve para adjetivar a Teseo: "Los años, luego, le confirieron esa peculiar majestad que tienen los canallas (...), los criminales venturosos e impunes." Pero todo criminal tiene que enfrentar un hecho jurídico...,es decir, "una justicia poética”, dice Borges.

2. Minor Calderón Salas. "El legado cultural de José Marti, Joaquín García Monge y Jorge Luis Borges expresado en el Repertorio Americano” (2001:17-18) dice acerca de la posición política de Borges lo siguiente: "A pesar de correr el riesgo de ser redundante, creo oportuno insistir en dos de los textos borgesianos del Repertorio Americano: "1941 " y "Una pedagogía del odio", en los cuales Borges asume una posición política contra el nazismo e instrumentaliza la palabra -la literatura- para denunciar la propagación del odio y del imperialismo de la Alemania de Hitler." Más adelante dice Calderón Salas: “Asimismo, y esto es muy importante, un Borges que denuncia el avance del nazismo y la propagación del odio por parte del tercer Reich. Es, por tanto, un Borges político o más bien politizado, tomando posición y denunciando un tipo de imperialismo." 
técnica asimétrica per se. ¿Quizá sea una cuestión cultural más que de pura técnica literaria? ¿Puede ser una práctica cultural e ideológica más que técnica?, o, ¿quizá sea la técnica del cuento erudito (como ficción pura) que se impone a la cultura?

Lo que sí queda claro es que la posición más acertada sería la de la inclusión que significaría permanecer dentro del sistema social y desarrollarse en él. Pero esto es una cuestión ética que el narrador debe decidir, a pesar de la erudición del cuento, tal como se verá en el desarrollo de este ensayo y no debe ser una imposición del lector o hacia el lector. Sin embargo, cabe preguntarse, ¿de parte de quién está el lector?

El mecanismo sociopolítico, cultural, ideológico de apoyo que se necesita es aquel que permita la inclusión de Asterión, visto como un discapacitado, incomprendido e incapaz de comunicarse. ¿Será un problema de Asterión o de la creación de barreras que impiden la participación social y cultural suya? El asunto es detectar las barreras pues hay escasa información o visión del mundo, pobreza de todo tipo, prejuicios, estereotipos, otros. Reconocerlos es un asunto importante, pues las barreras están quizá dentro de nosotros y por supuesto fuera también.

La inclusión es una estrategia para atender la diversidad social, afectiva, cultural, política, económica e ideológica, entre otras cosas. El relato en sí es un instrumento que llama la atención sobre eso, a propósito de los valores transversales.

III

En 1948 se dictó la Declaración Universal de los Derechos Humanos. Para entonces -y mucho antes- el panorama mundial y el costarricense, por ejemplo, era -y sigue siendo- de desigualdad en función del origen socioeconómico, geográfico, cultural, condición personal, física, de género, diversas discapacidades, educación; así también por cuestiones ideológicas, religión, políticas y raza ${ }^{3}$, entre otras... A pesar de esto, Costa Rica alcanzó algunos logros pero la exclusión educativa se presenta cuando no todos los habitantes del país tienen acceso a cualquiera de sus formas. El abandono de las aulas es otro ejemplo de proceso de exclusión del sistema. Se impone un currículo

3. Referido a la ideología, la política y la raza dice Iván Molina Jiménez en el libro Anticomunismo Reformista, competencia electoral y cuestión social en Costa Rica (1931-1948): para el caso de Centroamérica, en lo ideológico-político era excepcional que en 1935 en Costa Rica se permitiera la organización y libre operación del Partido Comunista y el Partido reformista de Jorge Volio. Pero, por otro lado, los pastores disidentes que apoyaban en lo social a Volio y cuestionaban al clero, fueron perseguidos. Como es de notar, en la esfera eclesiástica conservadora el discurso anticomunista también era feroz en sus publicaciones de tipo periodístico. Y no solo eso, con la misma saña se refería hacia los judíos polacos a quienes acusaban de 
normado e inflexible que obliga a actuar bajo un reglamento normalizado de evaluación.

Por tanto, se ve la diferencia como un déficit y no como un recurso. Se fomenta la competitividad (como metarrelato posmoderno) en lugar de la cooperación. Se promueve el individualismo (la fragmentación ideológica) y no hay proyectos transformadores totalizadores (como una ideología que aglutine a un conglomerado hacia meta). Es academicista, no cultural ni vivencial. Se le achaca el fracaso a la persona, no al sistema. Evalúa resultados, no procesos. Privilegia la medición, no la evaluación. La opinión del educador y del educando no cuenta. Priva la burocratización y la departamentalización del proceso educativo...

La etiqueta y la rotulación son formas de discriminación porque es una visión determinista centrada en el déficit y el currículo.

Por otro lado, el modelo exclusivo no es pluricultural ni intercultural puesto que no todas las identidades tienen valor, tal como se escribió en la cita de Iván Molina para el caso de Costa Rica. Entonces no se valora lo diverso como una posibilidad positiva sino lo desigual como problema. Por lo tanto, la inclusión debe ser una nueva visión de cualquier tipo de discapacidad o diversidad basada en el modelo social y en el principio de vida independiente. El modelo inclusivo es ético, ideológico y moral, opuesto a toda discriminación. Todos tenemos el derecho a ser, a hacer, a existir tal como somos. Debemos tolerarnos, respetarnos, convivir. Independiente de nuestra diversidad y condición, no es un problema ni una amenaza.

Se debe reconocer la noción de diversidad, dejar de actuar como si esta no existiera. Todas las identidades valen. Innovar, tener nuevos referentes, compromisos, prácticas culturales inclusivas, acogedoras, colaboradoras, estimulantes, de desarrollo, de erradicación de barreras dentro y fuera de nosotros... No hay respuestas simples ni universales para todos, en todo lugar y en toda época.

La inclusión es una forma de vivir, de vivir juntos, el conocido

comunistas y de financiar al partido de Manuel Mora, lo cual no se pudo probar. Misma acusación antisemita hizo el Diario de Costa Rica entre 1939-1940, cuyo dueño era Otilio Ulate. En cuanto a la razón étnica, Molina Jiménez dice que el discurso oficial costarricense fomentó el racismo y la xenofobia que se agravó conforme avanzaba la crisis de 1930. Los costarricenses, según el componente étnico, era una raza de piel blanca y sana (en peligro de contaminación debido a agentes externos, según el embajador de los estados Unidos en Costa Rica) que excluía a los “otros", ya se tratara de indígenas, afrocaribeños, chinos y judíos. Paradójicamente, señala Molina, el Clero costarricense tenía inclinaciones alemanas pues fue un alemán, el obispo Thiel, quien tenía posiciones fascistas, lo cual no era bien visto por la legación de Estados Unidos en Costa Rica, y ambos estaban en contra del comunismo. 
y el extraño, con el que es igual y el que no... En suma, es un construir juntos más que una ciencia, filosofía, educación, investigación, evaluación... Es un juicio de valor vivo, claro y sensible.

\section{IV}

El análisis de la competencia artística de "La casa de Asterión", de Borges, devela la clave estética para una lectura de la exclusión y la inclusión, desde el punto de vista de la ruptura del código del metarrelato ${ }^{4}$ del mito. Los actos quedan prendidos a un nuevo código de valor y la noción del mal deja de ser absoluta o universal y es sobre el sujeto ${ }^{5}$ que obra, según su espiritu y su circunstancia, sobre quien recae la condena o la compasión, la ignominia o el enternecimiento.

Borges ha sido capaz de extraer del mito antiguo dimensiones que, preexistiendo, resultan nuevas y personales. Es un punto fuerte en su estética. Borges encuentra en el otro, en la criatura de ficción, la manera de decir sus obsesiones, la identidad humana, el destino, el tiempo, la memoria, la paradoja, la soledad, la muerte... la exclusión de alguien que poco a poco perdió la vista. El Borges inquisidor y asombrado ante el laberinto de símbolos que es el universo, la mente, el arte y la vida. La versión mitológica es el traspaso fabulado del ritual hierogénico

4. Carlos Rojas Osorio, en La filosofia en el debate posmoderno (2003:299-302-305), observa acerca de los metarrelatos desde el punto de vista de Francois Lyotard, lo siguiente:"Un metarrelato es una forma de discurso cuya pretensión es abarcarlos todos, dominar las reglas de las distintas clases de enunciados y de los distintos géneros de discurso. Se trataría de un metalenguaje. Pero Lyotard nos dirá que no hay metalenguaje... La dialéctica absorbería en un único discurso toda otra forma enunciativa. Se trataría de una homogeneización del discurso, una falta de respeto a las diferencias." Pero no hay tal, lo que hay, dice Rojas Osorio, oponiéndose a Lyotard: "Es la legitimidad de las distintas formas de enunciados (...) No hay un género de discurso que los abarque a todos (...) Legitimamos entonces recurriendo al mito (como metarrelato, subrayo yo) (...) o a la revelación, o a la humanidad emancipada, o al proletariado mundial, etc."

5. Sobre el concepto del sujeto, Maynor Antonio Mora, en su libro Avatares del sujeto. Imaginación, intelecto, educación (2005), dice lo siguiente: existe un sujeto diferenciado de otras entidades y es, a la vez, un acto de reflexión identitaria en términos filosóficos; en el mercado capitalista el sujeto es una figura jurídica con identidad y referentes reales; en la instancia política el sujeto se inserta en la trama social con la que tiene un lazo político; en la esfera de la angustia existencial el sujeto se vincula a lo sicológico, a lo trascendente, de su retorno después del viaje por la estructura social en donde es "un eterno suprimido"; en la ciencia-ficción se resalta el papel de la imaginación en la construcción del sujeto y es en el mundo de la imaginación donde el sujeto reconstruye los mundos potenciales a los que aspira en los cuales él es ente carenciado, imperfecto, incompleto. Aspira a una potencial perfección a través del deseo y la utopía. El sujeto-intelectual es figura del sujeto-héroe moderno que, a su vez, es un dispositivo ético moderno mediante el cual se redime la insuficiencia de la realidad; su tarea creativa es comprender y explicar el mundo; la pedagógica es transmitir la verdad. Pero este mesianismo ya está siendo cuestionado en la eliminación de las dicotomías héroe/masa y saber/ignorancia a partir de la multiplicidad de lo mismo. 
del toro-sol (Minos) con la vaca-luna (Pasifae) para crear vida nueva: el Minotauro, ser híbrido de dios (toro) y rey (Minos). Desde la visión exclusiva: fiera y hombre. O retrocediendo en el tiempo propio de Hispanoamérica: barbarie-civilización ${ }^{6}$, con lo cual Borges resemantiza el mito y la utopía? Por tanto, en Borges la re-lectura del mito es un juego lúdico y un problema ético. Y se requiere un lector implícito, ágil, dispuesto y capaz de descifrar las referencias ocultas e interpretar el sentido de lo narrado a la luz de su experiencia y del contexto.

En el cuento en cuestión, se menciona la naturaleza celeste/divina del personaje como distractor; cito:

"Quizá yo he creado las estrellas y el sol y la enorme casa, pero ya no me acuerdo, dice Asterión". (Borges 1988:72).
En este mismo cuento, Asterión menciona su condición terrenal de hombre-toro con lo que a pesar de su amnesia ${ }^{8}$ no se define dónde debe situarse o dónde deben situarlo los otros, incluyendo el otro Asterión que él mismo inventa para jugar. Es decir, la idea celeste-terrenal es una condición asociada a la idea de exclusión / inclusión social. El mismo Asterión se autoexcluye al decir que su condición es de realeza frente al vulgo o bien cuando piensa que las letras no le son de importancia, con lo que su condición intelectiva también es motivo para ser excluido del poder de la letra escrita / escolaridad.

Para Asterión nada es comunicable a través del lenguaje escrito, creado para tender puentes con sus semejantes y compartir las individualidades para, obviamente, incluirse. La palabra es inservible cuando se

6. En un sentido llano, el concepto de civilización viene a ser en "La casa de Asterión" la referencia a la identidad de lo urbano. Paradójicamente, para el minotauro, más bien, es en lo urbano donde vive la grey o el vulgo (la barbarie). Pero el sentido más claro de que este relato de Borges es de identidad urbana está dado en la constitución de que es un cuento de corte policial, aunque el mismo Borges no lo haya dicho. $\mathrm{Y}$, por otro lado, que estos cuentos aparecieron en folletines o por entregas publicados en periódicos de distintas ciudades.

7. Carlos Rojas, op cit. (2003: 21-21), dice de la utopía/mito lo siguiente: "La crítica de la utopía caracteriza también al posmodernismo. Las utopías nacen de un afán racionalista de planificar el futuro y justificarlo de acuerdo con una metarrativa. Pero ya se ha visto que esas metarrativas son totalizantes/totalizadoras. La razón pare monstruos, según la expresión de Goya. Del mismo modo, las utopías nacidas de un racionalismo totalizador no produjeron más que monstruos absolutistas. Al lado de la muerte de los metarrelatos y de las ideologías existe también la idea de cierta recuperación del mito (...) El racionalismo mismo puede ser un mito (...) La dicotomía mito/razón pierde su fuerza tradicional.”

8. De manera irónica o ilustrativa, quizá, Borges (1978) contrasta a Asterión con el cuervo del poema de Poe, “El cuervo", "(que ya simplemente es emblema de la memoria, de la memoria desdichadamente inmortal)". 
trata de transmitir lo que de verdad importa a Asterión (y al ser humano), lo que puede salvarle del mundo múltiple y aparente en que vive: fracasa con el lenguaje. Su mal uso del lenguaje, del aprendizaje, la enseñanza escolar (si fuera el caso) y el mismo desconocimiento intelectual ${ }^{9}$ general lo margina o excluye.

\section{V}

En lo referido al texto y su mensaje: ¿Qué relata "La casa de Asterión”? ¿Cuál es su sentido íntimo? La más profunda esencia de Asterión, es él mismo, su soledad, su no ubicación, su incomunicabilidad y su amnesia. Borges, en El Aleph, dice:

"Lo que importa es la correspondencia de la casa monstruosa con el hablante monstruoso. El minotauro justifica con creces la existencia del laberinto". (Borges 1988:72).

La prisión de Asterión, su verdadero laberinto, es la monstruosidad física pero sobre todo espiritual, que lo encierra trágicamente en la soledad. Los determinismos ${ }^{10}$ lo avasallan. Es un monstruo, un híbrido de hombre-toro. Un día salió al mundo y este huyó despavorido. Él debe desandar el camino hacia su encierro: para Asterión, definitivamente no hay lugar en el mundo. Desprecia a los demás y la comunicación con ellos. Como se afirmó párrafos atrás, se autoexcluye.

No es prisionero de puertas o cerrojos (que de por sí permanecen abiertas, dice Asterión), sino de su individualidad definitiva: perderse en el

9. Maynor Antonio Mora, op cit. (2005), en la introducción de su libro, dice acerca del problema del conocimiento y la verdad que "Foucault introduce la idea de que todo sistema de conocimiento (hasta el más inocente) es también una estructura de subjetivación que crea sujetos y mundos. Así, la filosofía y la ciencia ocultan una trampa. Al darnos a la tarea de conocer, generamos procesos de normalización del mundo y del sujeto". Más adelante aclara que el problema está en debatir la "nulidad epistemológica de aquellas corrientes de pensamiento que explican el mundo, pero que no explican como es qué explican". Luego, sobre el intelectual dice: "El conocimiento consiste en autorreflexión sobre su producción. Esto es lo que propone Foucault; la otra opción del intelectual puede ser dedicarse a una profesión que no glorifique esa cuota de cinismo genético presente en la labor intelectual y en la labor de la pedagogía. No obstante, si el intelectual decide cambiar de trabajo, con ello no hace más que ocultar el problema ." Finalmente dice: El racionalismo a ultranza es irracional y desencadena la imposibilidad del discurso y la comunicación social.

10. Sobre el concepto de determinismo escojo el referido al literario por ser más apropiado. Dice Juan Durán Luzio, en Senderos de identidad (Diez ensayos sobre literatura costarricense (2003:121-124) a propósito de Un caso de relación literaria: Emile Zola y Joaquín García Monge, que Claude Bernard aporta la tesis central del "Determinismo" que fue recogida por Emile Zola y que "no es lo mismo" de la que hablaba Hipolyte Taine. Se trata, según Durán Luzio, de reconocer las causas que rigen y determinan la aparición de los fenómenos; su fin, como apunta Zola, "consiste en descubrir las relaciones que ligan un fenómeno cualquiera a su causa proxima o, dicho de otro modo, consiste en determinar las condiciones necesarias 
laberinto de su propio yo. Asunto ontológico y existencial importante. La supervivencia está solo asegurada en el interior; solo en la comunicación con las otras cosas y seres del universo se sentirá incluido. Lo intenta pero fracasa. Por lo tanto le sobreviene la muerte simbólica.

La muerte es salvación, paz, alivio, salida definitiva del laberinto de la vida, paraíso de qué: de la nada. Se pierde la vida y se va el dolor. En el no-existir no hay laberintos, traspasa la puerta hacia la dicha del no ser: la anulación.

Él vive su soledad con dolor, la ternura con que entretiene el tiempo jugando o imagina "otro Asterión" que lo visita y le muestra los recovecos de la casa, la impaciencia conmovedora con que ansía la llegada de su libertador. Hay un nihilismo, un determinismo, una fatalidad en la idea de Borges, de que Asterión se decante como un ser que nació para sufrir. Este es un criterio simbólico de Borges para decir que en la realidad lo que se crítica es el sistema político, ético, humano, ideológico, social y educativo, entre otras cosas, de la exclusión.

\section{VI}

La inclusión es una primera ruptura y una novedad del código estético en "La casa de Asterión". Como tal, el cuento tiene una base mitológica más antigua que la griega. Quizá asiria-babilónica, fenicia, cartaginesa, mesopotámica e, incluso, persa. En estas civilizaciones ya se narraban hechos como el diluvio, que siglos después será retomado en la tradición griega y la judeo-cristiana.

Mencionan, siglos antes, las puertas de los siete recintos infernales, como siete son los días de la semana de nuestro calendario... y que en el relato de Borges es el número catorce, número perfecto.

En Fenicia se documentó a Astarté como Ariadna; en Asiria es Istar. Es la diosa del amor, aunque a Ariadna se le ha visto más como el símbolo de la inteligencia al proponerle a Teseo el hilo conductor de la resolución del espejismo del laberinto. Pero esta inteligencia la hace cómplice del crimen de Teseo.

Como se nota, la variedad de mitos se produce en estas culturas por la falta de unidad política. Es por ello que bajo nombres diferentes se ocultan

para que se produzca este fenómeno..." En este sentido, la documentación anulaba la imaginación y "la idealización irrestricta e imaginaria del mundo resultaba inaceptable. Por eso oponen a las abstracciones el documento; a la imaginación, la tesis; a los espacios exóticos, la realidad inmediata. Observar no es inventar (...) todo consiste en aprehender la naturaleza para expresarla". Más adelante Durán Luzio afirma que al escritor naturalista le compete el aspecto oscuro del hombre: lo morboso". 
las mismas deidades, una especie de sincretismo, más relacionada con la religión y no con una explicación del origen del ser humano o el cosmos; más como instrumento político-ideológico que como leyenda o relato simbólico de héroes ejemplares.

La segunda ruptura es la inversión de las funciones actanciales de los personajes del cuento. Teseo es un héroe menor en la mitología griega; en el relato de Borges pasa por redentor, a propósito de la técnica del relato policial, pero hay que pensarlo como antagonista (una especie de Dios castigador que cae sobre Asterión, como en el poema de Vallejos, "Los heraldos negros"11) y al minotauro como protagonista. Quizá esto no sea novedoso, es lineal si se quiere. Pero la tradición literaria puede ver en Teseo un héroe "mata bichos" y Ariadna (la hermanastra de Asterión) es la apoteosis transitoria de
Teseo, a quien abandona en la isla de Naxos porque Teseo se va con Fedra, a la que también abandona para irse con su amante masculino Hipólito.

Entonces, en el minotauro, en la inversión de las funciones actanciales, bien puede ser engañosa la idea contraria de verlo como el antagonista y darle a Teseo el protagonismo por aniquilarlo. Pero, se insiste, esta es una apreciación que Borges no ve así. Para él es como se dijo en el párrafo precedente. Quizá el lector común vea al minotauro como un antagonista por su fealdad y su sed de sangre, que debe morir también por su soberbia y vanidad. Pero, al ser excluido, alcanza el nivel protagónico que realmente Borges nos quiere señalar se halla encerrado en un laberinto, palabra que al parecer no es griega y podría significar poesía o baile de intrincada o difícil estructura ${ }^{12}$. Lo que interesa es que a partir de una lectura del cuento

11. Aquí Asterión adquiere una dimensión Existencialista, tal vez más como concepción vital que una técnica literaria para presentar al personaje en su circunstancia de ser un ser excluido. Aunque para los existencialistas el hombre no cuenta con una esencia anterior a su existencia, que por sí misma no tiene ningún sentido, es absurda. La responsabilidad del hombre es, entonces, tomar conciencia de esto y darse su propia esencia, asignándole un sentido propio y auténtico a su existencia. ¿Podrá Asterión aspirar a eso? ¿Quizás la muerte lo sorprendió en medio de esa toma de conciencia? Eso no lo sabremos nunca. Tal como sucede en el relato "La vida feliz de Francis Macomber", de Hemingway (1968).

Como este mundo es nuestra circunstancia, el sentido que le demos a nuestra existencia debe ser fiel a esa circunstancia. El hombre auténtico no se evadirá mediante creencias en ningún tipo de fuerzas supraterrenales, sino que estará orgulloso de su condición terrena y finita. Asterión, a partir del metarrelato de la profecía u oráculo que le hace un joven antes de morir ya está en camino de su finitud y la ansia. Como las circunstancias de cada hombre no son las mismas, en el campo de las relaciones humanas el problema de la comunicación entre los hombres, que desde este punto de vista se vuelve prácticamente imposible, es un tema, de entre otros, para los existencialistas pero también para los que no lo son. Ya me referí al asunto de la falta de lectura de Asterión y su desdén por las letras lo que lo autoexcluye de toda posible comunicación.

12. Sobre el concepto de laberinto como espacio cerrado (lugar del asesinato de Asterión) hay mucha literatura. No obstante, interesa destacar el carácter espacial y cerrado de este. Justo Navarro, en Hitos de la literatura 
de Borges se devele un ritual porque el acto de la muerte sagrada ${ }^{13}$ de los hombres jóvenes y/o doncellas, así como la del mismo minotauro, por ejemplo, se reactualice y resemantice como todo mito.

Pero desde la óptica de la inclusión se descubre el "engaño": Teseo representa a la sociedad indefensa o grey (masificada) que excluye al monstruo por varias cosas: su incapacidad comunicativa, su aspecto físico, por ser hijo ilegítimo $\mathrm{y}$ vergonzoso de una reina y un toro salido del mar, hijo de Poseidón, a quien el legítimo padre de Asterión, Minos, no quiso matar. Minos es hijo adoptivo de Asterión y Europa. Más adelante intervienen otros personajes como Dédalo que inventó una vaca de madera donde se introdujo Pasifae para quedar preñada del toro. Luego, Heracles cautivó al toro, se lo llevó a Teseo para que lo matara. Así, Borges relata que existe un redentor del minotauro.

Así, ante tanto delirio, Minos le pide a Dédalo un lugar para huir y este le construye el laberinto-cárcel. Es la autoexclusión.

En el tercer núcleo significativo, volviendo al análisis crítico del código, Borges rompe la tradición al humanizar al minotauro, y a Teseo -ya humano- lo pone en el plano de la violencia (igual a como lo retratan los mitos) por darle muerte a Asterión y a la exclusión social por

criminal (2005), dice al respecto de este tipo de espacios cerrados y los crímenes documentados en la Literatura Criminal o Negra: "Casi todos los crímenes ocurren en mundos cerrados, porque es imposible pensar que un asesino pueda colarse en un cuarto apestillado, un compartimiento del Orient Express, una familia perfecta o la abadía medieval de Humberto Eco." O, como dice Borges (1978) a propósito del poema "El Cuervo”, de Poe: “(...) la unidad de su poema necesitaba un recinto cerrado".

Por otro lado, a modo de insistencia, la tradición literaria y psicoanalítica ha visto en el laberinto el espacio de la casa-madre. El vientre materno del cual el hijo o la hija no quiere o no pude salir.

A propósito de la casa-madre problematizada o en crisis, Antonio Castillo (2005), sobre un poemario del escritor costarricense Adriano Corrales, La caza del poeta, dice lo siguiente: "Ahora la casa del Poeta, que es la casa de todos, está en inminente peligro. Su escenario natural es víctima de nuevos despojos, no digamos su fauna y su flora, pero lo más indignante es el despojo humano. Además, está invadida por la ciudad, santuario aquel en donde la publicidad posmoderna, enajenante y alienante, idiotiza al individuo y lo arranca de su pasado, de su memoria, de la colectividad humana, que es donde está la salvación de nuestros valores, nuestra idiosincrasia y la Casa del Poeta, que es la Casa Madre (...).

Luego, Castillo, dice que también están en crisis "la patria, nuestra Casa Madre" ... "desde hace siglos, y que en la actualidad es descollante por el grado de deshumanización a que hemos sido sometidos..."

13. Quizá el aspecto de lo sagrado va en la dirección del "nuevo subgénero rampante de la novela de intriga religiosa", al decir de Justo Navarro (2005), referido El nombre de la rosa (1980), de Umberto Eco, con sus monjes envenenados de erudición, dice Navarro. Finalmente apunta: “...el poeta cristiano Auden lo escribió: la imagen de toda novela policiaca es la búsqueda del Grial, y así la tradición del género se remonta a las leyendas de los Caballeros de la Tabla Redonda. Estamos ansiosos de verdades históricas y consecuentemente leemos con devoción obras como El código Da Vinci de Dan Brown." 
incapacidad del mismo Asterión para comunicarse con Ariadna, su hermanastra. Pero, ella, es cómplice del asesinato del hermano / vergüenza y deshonra. Es decir, también comete el pecado de la exclusión.

La cuarta significación es la originalidad de Borges para resemantizar el mito y romper con su visión totalizadora. Hay una conciencia de la inclusión social como una alternativa política, civilizadora, ética y estética.

Un quinto elemento es concentrar en este relato la atención de la historia narrada en un elemento determinado: el asedio psicológico y social del minotauro, representado en las interrogantes o dudas, que se constituyen en el motor de las acciones del cuento. Asimismo, las emociones de Asterión (asunto psicológico quizás) son armadas para favorecer lo relatado y derivar luego en tragedia, con lo que se ve la maestría de Borges para manejar la técnica narrativa y tensional del cuento. Por encima de la violencia se trasluce la humanidad, con lo que el código del mito pierde fuerza y gana la ficción literaria ${ }^{14}$. Se salva lo estético, no lo ritual ni mítico. Gana más aún lo lúdico.

En ese sentido, Teseo como redentor engaña al lector, quien cree que este de verdad viene a liberar al monstruo de su condición. Esta calma aparente es superficial. Borges se gana la simpatía del lector no ilustrado. La verdad es otra. Lo fabulesco esconde la crítica social. Teseo no es inocente. Este, en lugar de acercarse a la humanidad casi aniñada del minotauro y sensibilizarse con él, lo mata inducido por la vergüenza social de las mujeres: Ariadna y Pasifae. Es decir, el complejo de Edipo se despliega como un prodigio: el minotauro es "despechado" o lo obligan a romper dolorosamente con las figuras maternales o femeninas que lo circundan $\mathrm{y}$, quien sabe si no, lo circundaron de manera ritual-simbólica.

Lo edípico se presenta también en el paso de lo animal-biológico del ser humano (Asterión) a lo cultural-civilizatorio (Teseo-espada). El ser humano se instaura en el mundo social. Esto es significativo y tal

14. Sobre la ficción narrativa y la realidad de los crímenes, Justo Navarro, op cit. (2005) dice lo siguiente: "Una vez le preguntaron a Raymond Chandler si sus novelas ofrecían una visión verdadera del mundo del delito, y Chandler dijo que sólo exageraban literariamente el aspecto melodramático de la corrupción real. El melodrama era la materia prima del autor de novelas policiacas, un especialista en exagerar la violencia y el miedo. El realismo del género policiaco es superficial. La literatura de crímenes ha tenido una tendencia histórica al disparate desde sus comienzos, y así lo demuestra el orangután culpable de "Los asesinatos de la calle Morgue" (1841), una de las tres historias del caballero Auguste Dupin, de Poe". Borges (1978) refuerza esta idea al decir: "Tenemos, pues, al relato policial como un género intelectual. Como un género basado en algo totalmente ficticio; el hecho es que un crimen es descubierto por un razonador abstracto y no por delaciones, por descuidos de los criminales." 
adaptación se llama pulsión de vida. Pero, es en la renuncia o la liberación donde termina la lucha de poder padre-hijo o madre-hijo. El hijo por sí solo se adapta a la sociedad o es excluido. La inadaptación se llama pulsión de muerte, que es la exclusión social como muerte simbólica y mítica. El minotauro se sabe excluido desde un inicio, no teme por su vida $y$ desea la verdad. ¿Acaso no hay una moral castigadora como en los cuentos infantiles antiguos o en el Existencialismo más angustiante?

El sexto cuestionamiento, sin embargo, va dirigido a lo que parece que es pero no es por la vía de la ruptura del código del complejo de
Edipo antes tratado, en donde mito / complejo no tienen razón de ser lo mismo. Antonio Tulián (2007), en el prólogo al Edipo Rey-Electra, de Sófocles, ilustra esta apreciación:

"El habitante moderno refiere ese mito, habitualmente, al complejo de Edipo, una construcción teórica de Sigmund Freud a la base del psicoanálisis. (...) El mito de Edipo, al igual que la obra Edipo Rey (circa 430 a.C.), de Sófocles, poco tienen que ver con la lectura freudiana que resignifica la metáfora en sus aspectos sexuales, entre otros. Edipo es un mito que puede leerse desde la lucha por el poder o como una delicada intriga policial ${ }^{15}$. Tanto es un

15. "La casa de Asterión" es un cuento policial, según entreveo, sustentado en el metarrelato de un mito antiguo, lo cual es el andamiaje para que Borges despliegue la trama. Este relato como otros de Borges tienen el mismo sello. Asistimos a la confesión de un criminal que acaba de matar a un hombre-bestia, que también era un asesino en serie, al final del cuento, o como en El túnel, de Sábato, al inicio de la novela. Nada justifica la violencia con más violencia. En este sentido, ¿sería falso decir que Teseo es un héroe y que su asesinato está justificado solo porque Asterión era un asesino de jóvenes o un soberbio hijo de una reina? Quizá Justo Navarro op cit. (2005), aclare el asunto con esta cita: "Patricia Haighsmith tuvo la amplitud de espíritu de crear un asesino triunfante, Tom Ripley, insolente y audaz...en A pleno sol (1955)." Luego de matar a quien lo heredaba, el asesino, ya millonario en A pleno sol, se iba a vivir a París. Por lo tanto, quizá Teseo no es nada diferente y se va con Ariadna..., la vida sigue.

¿Qué sentido tiene que Borges como Sábato aporten el dato del asesino? Justo Navarro op cit.(2005), dice al respecto: "La prensa, clave de la realidad inmediata, puede ayudar a resolver un crimen (...) No hay que salir de la habitación para descubrir asesinos: el investigador puede ser el preso de Borges y Bioy (...) No hay que ver la escena del crimen: las apariencias engañan. El detective Max Carrados era ciego (...) El vigente modelo europeo y latinoamericano de literatura criminal es periodístico, moral y sociológico."

Por otro lado el cuento policial es aquel estructurado desde la deducción lógica que identifica al autor de un delito y revela sus móviles. Pero este relato no es nada sin la participación del lector en desentrañar el misterio quien debe ingresar en el mismo como un investigador más. Pero, se insiste, si el asesino viene identificado: ¿qué papel juega el lector? Borges (1978), lo aclara asï, al referirse a "Los crímenes de la calle Morgue": "Pero esta solución no es solución para nosotros, porque todos nosotros conocemos el argumento antes de leer el cuento de Poe. Eso, desde luego, le resta mucha fuerza (...) y luego se descubre el crimen; se descubre, pero nosotros ya sabemos la solución (...) Por eso podemos pensar mal de Poe, podemos pensar que sus argumentos son tan tenues que parecen transparentes. Lo son para nosotros, que ya los conocemos, pero no para los primeros lectores de ficciones policiales; no estaban educados como 
drama filosófico del hombre que se busca a sí mismo, que indaga sobre su identidad, como una metáfora de la búsqueda inclaudicable de la verdad, aunque ese camino conduzca al propio exterminio. Puede, desde $y a$, verse como un dilema psicológico, interpretación absolutamente alejada del ideario de Sófocles (...) La obra de Sófocles es la historia de una denodada búsqueda de la identidad: la del asesino y, desde ya, la del mismo protagonista. Es la indagación de un personaje sobre su pasado, sin pensar que ese bucear terminará destruyéndolo. Es además la parábola de la ceguera de un hombre ante la evidencia y, más allá de eso, sobre la honesta lucha intelectual de un individuo por conocer la verdad (...), leer Edipo Rey como la materialización de la teoría freudiana no solo es un error, sino que despoja a la tragedia de su significado verdadero y profundo(...) El complejo de Edipo, según Freud, es el resumen de las tendencias libidinales socialmente inaceptables de la primera infancia, y constituye el complejo nuclear de la neurosis (...) La tarea terapéutica consiste en encontrar sustitutos socialmente aceptables de su madre y reconciliarse con su padre." (Borges 1988:72).

El sétimo elemento no es menos violento ${ }^{16} \mathrm{o}$ "neurótico". Cuando salimos de la tomadura de pelo, en donde no hay vencedor ni vencido, asistimos con estupor al duelo por los muertos, o lo que es peor, los excluidos humana, política, social y culturalmente. Borges envía un mensaje claro: cuando el ser humano elimine a los monstruos externos a él (Teseo), los que lo rodean y lo fastidian o no lo fastidian; seguirá con los monstruos internos

nosotros, no eran una invención de Poe como lo somos nosotros. Nosotros, al leer una novela policial, somos una invención de Edgar Allan Poe. Los que leyeron ese cuento se quedaron maravillados y luego vinieron los otros".

Con respecto a la apreciación de Borges, sobre la pérdida de fuerza del relato de Poe, si esto se toma literalmente para "La casa de Asterión", de cierta forma técnica se ajusta pero el texto debe, pues, ganar en la visión Humanista de la Inclusión social. Esto lo digo por la razón de la idea de los equilibrios. O se gana en la técnica del relato y su aparato lingüístico o se gana en contenido, pero el relato no puede quedar al descubierto en alguna.

16. Sobre la violencia en el relato policial Borges (1978) dice que en Inglaterra aún se escriben cuentos "tranquilos" y que en Estados Unidos el cuento policial ya desapareció o se desvirtuó. De él mismo dice lo siguiente: "He intentado el género policial alguna vez, no estoy demasiado orgulloso de lo que he hecho. Lo he llevado a un terreno simbólico que no sé si cuadra. He escrito La muerte y la brújula. Algún texto policial con Bioy Casares, cuyos cuentos son muy superiores a los míos. Los cuentos de Isidro Parodi, que es un preso que, desde la cárcel, resuelve los crímenes."

Sin embargo, en este ensayo me he empeñado ya suficientemente en señalar que "La casa de Asterión" también deviene en cuento policial y que Borges no lo nombra como tal. No tiene porqué, esa es una apreciación mía pero parece "cuadrar", habría que sustentar esta hipótesis con más profundidad en otra investigación. 
que lo consumen desde el momento en que fue engendrado porque la exclusión la llevamos dentro como una etiqueta, al estilo del mismo Asterión desde su mítico y confuso origen hombre-bestia y, luego, ¿quién será testigo del vacío del mundo, de su propio final?

El octavo enfoque está centrado en el lector. Borges no ha dejado nada al azar. La recuperación del mito y su consiguiente resignificación es una tarea pedagógica ${ }^{17}$. No se priva al lector de conocer el mito, se le instruye en su sistema simbólico. Por tanto, lector y lectura convergen en una suerte de inclusión. El lector, no avisado, sin embargo, esperaría un final feliz... pero que se troca en desgracia futura al quedarse con un asesino como héroe y mandar a la tumba al minotauro. Aquí Borges se aleja de la lectura de exclusión porque no margina al lector de cierta forma de construcción del sentido del texto o de un tratamiento del texto desde cierto programa estandarizado, de cierto enfoque formalista y no artístico, ético, político, etc.

Dicho de otra manera, al lector no se le excluye del acceso a textos de calidad estética a cambio de otros en que lo artístico no sea fundamental o el dispositivo crítico-analítico se soslaye. Borges trabaja en la dirección de la inclusión mostrando el lado (morboso) de la exclusión o la marginación. Pero él no hace esta tarea por caridad o por beneficencia hacia el lector. Es un asunto más lúdi$\mathrm{co}^{18}$, de actitud, de conceptualización $\mathrm{y}$ de procedimiento literario.

\section{VII}

Enlazado con los párrafos precedentes, dice Sábato (1997, 180183), que el hombre vivía en una mentalidad primitiva o prelógica en camino a una conciencia positiva, cuyo final es la coexistencia de

17. Maynor Antonio Mora, op cit. (2005:14), dice acerca de la pedagogía lo siguiente: la educación no es un mecanismo de creación del sujeto, como instrumento potencial para la reconquista de la libertad y para la liberación de la subjetividad. Es la idea de convertir la caverna en conciencia, lo cual no sucedió. El saber especializado y el del intelectual están en crisis y, al menos, el intelectual debe "cambiar en pos de una pedagogía comunicativa que dirima de una vez por todas, la diferencia entre "sapiencia" e "ignorancia", mediante la construcción de relaciones de conocimiento democráticas, inclusivas y epistemológicamente sustentadas en una permanente labor crítica".

18. Con respecto a lo lúdico, a la participación activa del lector frente a los cuentos policiales, Borges, en la Conferencia en la Universidad argentina de Belgrano del 16 de junio de 1978, dice: "Aquí tenemos otra tradición del cuento policial: el hecho de un misterio descubierto por obra de la inteligencia, por una operación intelectual (...) Todo eso ya está en ese primer relato policial que escribió Poe, sin saber que inauguraba un género, llamado “The Murders in the Rue Morgue (Los crimenes de la calle Morgue”). Poe no quería que el género policial fuera un género realista, quería que fuera un género intelectual, un género fantástico si ustedes quieren, pero un género fantástico de la inteligencia, no de la imaginación solamente; de ambas cosas desde luego, pero sobre todo de la inteligencia. 
ambas en cualquier época y cultura. Para la Ilustración el ser humano progresaba en la medida en que se alejaba del estadio mito-poético. Es decir, desprovisto de racionalidad, el pensamiento puro se refugió en la literatura, lo que es una profanación pero, a la vez, una reivindicación del mito. De ahí se extrae la idea de que el pensamiento racional coexiste con el mágico. Por tanto, se convalida la necesidad en Borges de mostrarnos un mito del Minotauro reinventado en lo que de Humano puede existir en la ficción fantástica. Esta apariencia de la literariedad hay que evadirla o alejarse un poco de ella para disfrutarla desde otro ángulo. Concordando con Minor Calderón (2001), hay que resarcirle a Borges lo politizado de su literatura en lo Humano de su propuesta ético-estética. De tal modo que el mito no es un superfluo disparate. Pero tampoco tiene que ser teórico ni dar verdades científicas ni lógicas. Por eso es más cercano a lo literario. A la literatura fantástica y simbólica borgesiana. Como en la literatura de Borges lo mítico provoca pavor; la exclusión social también. Si la filosofía racionalista desdeña del mito ese imaginario que considera morboso, qué dirá de la exclusión social que muchas veces nos parece fantasía-mítica en donde alguien por su condición física, social, económica, etc... sea igualmente desechado socialmente; vale decir, aniquilado como hizo Teseo con Asterión.

\section{VIII}

Se propone, en Borges, una literatura de la esperanza en su ficcionalidad. ¿Qué obliga a pensar lo contrario? Ya se ha intentado conciliar la visión de la pedagogía inclusiva con la postura político-humanista de la ética-estética de la ficcionalidad de Borges como ruptura del código que ha visto en la literatura de este argentino universal pura geometría fantástica, casi matemática y fría . Esto hay que verlo de cerca.

Inicialmente todo escritor ejerce su oficio en un mundo en crisis permanente desde la radicalización de la religión hasta el paso de lo profano (Edad Media/Renacimiento); desde la angustia hasta la soledad (Edad Contemporánea); desde la enajenación del individuo a su fragmentación simbólica (Modernidad/Posmodernidad). En pocas palabras: Dios, la ciencia y el Capitalismo (con su brazo posmoderno) fueron el tema por tratar en lo literario y en lo cultural: la utopía y el nihilismo.

Si el panorama anterior es universal, es falso decir que Borges es un escritor individualista. Es cierto que opera su propia conciencia pero lo hace aludida a hechos exteriores, eso es inevitable. Por tanto, lo creado por el sujeto escritor atañe al mundo sociocultural que lo circunda. No es un asunto de puro individualismo preformulado o acomodado a la falta de compromiso social. El escritor, no 
solo Borges, vive en una comunidad llena de contradicciones y distorsiones históricas; míticas y utópicas, unas; bajo el influjo de la tiranía del racionalismo, otras. El escritor, dice Sábato, exagera estas circunstancias. Queda aquí explicada la característica de los cuentos policiales que exageran la criminalidad real existente en el mundo en aras de una escritura marcadamente rentable o consumible, tanto espiritual o intelectualmente como en la cultura universal.

Por otro lado, Borges no es un filósofo en el sentido estricto de la formación filosófica. Esto despertó en círculos intelectuales marxistas un repudio o excomulgación hacia él. Cosa extraña porque todos sabemos que en el mundo existen grandes escritores que son de orientación burguesa admirados por los marxistas y viceversa. Eso no es un secreto pero tampoco es algo que se dice a gritos, existe solamente. Son prejuicios, represiones, más culturales que otra cosa, ni siquiera ideológicos, imaginamos que diría Freud.

Según Sábato, en Borges lo que hay es una diversión estética de la filosofía. Digamos que no es una pureza contemplativa ni racionalista per $s e$. Es decir, saca partido de la filosofía para armar sus escritos. Probablemente el lector se asombre de lo divertido y pedagógico que pudo haber sido asistir a un curso de filosofía con Borges. Basta con leer cualquiera de sus conferencias magistrales, como en Barcelona o en Buenos Aires. Esto es, Borges traduce al código literario el "frío" código de la filosofía, entonces desmitifica lo filosófico. Lo hace accesible al lector no entrenado. De ahí que en al final del apartado VI se hace una mención del Borges magistral que apasiona al lector al tomarlo en cuenta y guiarlo por un sendero estético flexible.

Esta postura lúdica-cognoscitiva va y viene de lo real a lo fantástico por el camino del discurso estético. No hay que quebrarse la cabeza, parece que nos dice al oído, juegue, no más. Calcule, geometrice, trace líneas y cuando ya las tenga bien limpias y rectas tuérzalas, hágalas oblicuas... El intelecto que usted ponga en esa faena es solo para divertir y advertir la burla sana, crear armonías pasajeras, la idea, dice Sábato, es crear un ingenioso universo con posibilidades metafísicas en las que ni el mismo cree. ¿Por qué va a creer si es solo literatura o un juego discursivo simbólico en lo que todo vale y no vale? Verosimilitud pura es la palabra de respuesta.

Tal verosimilitud trae consigo el estigma del racionalismo. El es y no el parecer. No por ser verosimilitud dejará de ser susceptible de verificación, incluso matemática si fuera posible. En el fondo estoy hablando de cuentos como "La muerte y la brújula". Un detective que calcula, "regla en mano" su muerte y no puede creer el resultado matemático que le 
sobrevendrá. Dice Sábato $(1997,72)$, como los criminales, Borges, ama la simetría, el rigor, el diagrama, el silogismo; piensa y ejecuta un plan matemático (...) que termina con una demostración o se demuestra un teorema. ¿Acaso no hicieron lo mismo las antiguas civilizaciones al calcular planetas apenas vistos por el ojo? Nada tiene de exagerado ver en estos cuentos de Borges tales simetrías siniestras. "La casa de Asterión" está lleno de ejemplos. Hay un antes y un después. En el medio hay conjeturas, enlaces, equidistancias, redes lógicas, previsiones, rastreos de datos, pistas, conjeturas...Sí, pero no olvidemos que es ficcionalidad que aspira a derrotar la inderrotable realidad.

La casa de Asterión" es un juego de intrigas. También encerrado en su laberinto el Minotauro conjetura, juega, teoriza... Se hace humano por lúdico, no importa si es medio monstruo y medio humano, eso es fachada. La matemática es eso, lo que interesa es el resultado no el medio para llegar. Y como el medio ya se descifró metódicamente (conjeturas, enlaces...) también simétricamente, la realidad empieza a tomar forma. A englobarlo. A intrigarlo. A rodearlo de formas perfectibles y se conmueve. Inicia el viaje hacia la ruta de Asterión excluido. Aparece el existencialismo angustiante, el determinismo, el nihilismo, el monstruo interior de Kafka, la pulsión de muerte de Freud, el rechazo racial, político... Borges entrevé que el formalismo estético empieza a darle razones para el sentido humano de sus cuentos, principalmente las contradicciones y el lenguaje con sus inagotables significaciones.

Pero, Borges sigue atrapado: contradicciones y lenguaje son ilusorios. ¿Cómo salir de aquí? Se desliza por la puerta del Humanismo. De la imperfección. De lo impuro. Quizás vacile. Inventa una Idealismo (la monstruosa cabeza del toro) y un Humanismo (el cuerpo del hombre). Le antepone seres completos igual de imperfectos humanos: Teseo-Ariadna desprovistos de Humanidad. Para Borges tales situaciones son vanas. Al respecto, apoyados en Sábato (1997, 78) se puede decir que ni una ni otra cosa es lo importante, sino una región intermedia: el alma.

"En ella se da el amor y el odio, el mito y la ficción, la esperanza y el sueño (...) Ambigua y angustiada, el alma sufre entre la carne y la razón dominada por las pasiones del cuerpo mortal y aspirando a la eternidad del espíritu, perpetuamente vacilante entre lo relativo y lo absoluto, entre la corrupción y la inmortalidad, entre lo diabólico y lo divino. El arte y la poesía surgen de esa confusa región y a causa de esa misma confusión: un dios no escribe novelas".

Para Borges todo aquello sonaría a inútil barbarie; pero es lo que hay. Cosas sutiles pero reales. Humildes quizás; pero humanas. ¿Cómo 
escapar de lo humano? Solo volando a la eternidad, como en el poema "Vuelo supremo" de Julián Marchena. O construyendo bibliotecas, laberintos, fantasmas que sufren de palabra, dice Sábato.

Por supuesto que esta lectura del código estético en Borges también está en el Quijote, y su locura es un signo de descrédito social; en El moto de García Monge, su viaje determinista a las Salinas sella la exclusión social y económica de su existir; Única mirando al mar, de Fernando Contreras, es un torbellino de seres desechados que se animan entre sí para luchar entre la basura de San José contra la exclusión total. La lista es interminable; otros ejemplos son los viejitos de "Por el amor de Dios", de Dobles Segrega o los de La mala sombra y otros cuentos, de García Monge. Ejemplos sobran y ya el lector tiene en mente su lista.

Todo explica el final. Parafraseando a Sábato: en Borges hay cuerpo, alma y literatura, por un lado; por otro, geometría y filosofía imaginaria; y también: Humanismo e inclusión pese a la morbosa realidad.

\section{Bibliografía}

Calderón Salas, Minor. El legado cultural de José Martí, Joaquín García Monge y Jorge Luis Borges expresado en el Repertorio Americano, en Repertorio Americano, Nueva Época. $\mathrm{N}^{\circ} 11$, enero-junio del 2001. UNA-IDELA, Heredia, Costa Rica.
Borges, Jorge Luis. "La casa de Asterión", en El Aleph. Buenos Aires, Alianza Editorial, 1988. Pág. 69-72.

Borges, Jorge Luis. "El espantoso redentor Lazarus Morell", en Historia universal de la infamia, Madrid, Alianza Editorial, 1975.

Borges, Jorge Luis. Conferencia en la Universidad argentina de Belgrano, 16 de junio de 1978.

Durán Luzio, Juan. Senderos de identidad (Diez ensayos sobre literatura costarricense). San José, Costa Rica, ECR, 2003.

Hemingway, Ernest. Relatos. Barcelona, Libros Reno (difundido por Plaza \& Janes S. A.), 1968.

Molina Jiménez, Iván. Anticomunismo Reformista, competencia electoral y cuestión social en Costa Rica (1931-1948): para el caso de Centroamérica. San José, Costa Rica, ECR, 2007.

Mora, Maynor Antonio. Avatares del sujeto. Imaginación, intelecto, educación. Universidad Nacional, Heredia, EUNA, 2005.

Navarro, Justo. Hitos de la literatura criminal, en suplemento Los libros, Semanario Universidad, setiembre 2005. San José, Costa Rica.

Rojas Osorio, Carlos. La filosofía en el debate posmoderno. Universidad Nacional, Heredia, EUNA, 2003.

Sábato, Ernesto. El escritor y sus fantasmas. Barcelona, Editorial Seix Barral, S.A., 1997.

Sófocles. Edipo Rey-Electra. Prólogo de Antonio Tulián. Buenos Aires, Langseller, 2007. 
